\title{
Designing Dual Language Books for Children in the United Kingdom Schools
}

\author{
Huiying Zheng \\ Chengdu Hanabi Visual Brand Management Co. Ltd., Chengdu, China \\ Email: mlbsabc@sina.com
}

How to cite this paper: Zheng, H. Y. (2019). Designing Dual Language Books for Children in the United Kingdom Schools. Art and Design Review, 7, 78-88. https://doi.org/10.4236/adr.2019.72008

Received: February 19, 2019

Accepted: May 14, 2019

Published: May 17, 2019

Copyright $\odot 2019$ by author(s) and Scientific Research Publishing Inc. This work is licensed under the Creative Commons Attribution International License (CC BY 4.0).

http://creativecommons.org/licenses/by/4.0/

\begin{abstract}
Scientifically designed dual language books are the premise and basis for ensuring smooth bilingual teaching. To design dual language books for children in Britain, it is necessary to fully consider the practicality of their books and meet the actual needs of schools. The dual language books should be easy to learn and teach, practical and interesting, so as to meet the bilingual learning needs of British children. This essay will cut into the resources of the UK's major language communities and discuss the various factors that influence the design of dual language books, and related issues identified by the research project.
\end{abstract}

\section{Keywords}

Dual Language Books, Designing, British Primary Schools, Pictures

\section{Introduction}

The following essay focuses on better understanding the need for dual language books in the primary schools of Britain and it analyzes the key of the design issues shown in these books. The essay demonstrates that designing effective dual language books requires a considerable amount of equity that is focused on the equal restructuring of different languages. Moreover, it reveals that successful dual language books are those which can not only effectively respond to needs but also take into consideration the placement of pictures and the direction of reading. This essay focuses on the resources produced for the main language communities in the UK where dual language books with non-Latin scripts are needed (Urdu, Gujarati, Punjabi, Cantonese and Mandarin). It identifies various factors influencing dual language book design and discusses related issues that have been identified by research projects such as the Multilingual Resources for Children Project, conducted at the University of Reading in 1995. This essay first 
describes what dual language books are, then explains the need for dual language books in UK primary schools, then illustrates diversification of value orientation and flexibility in the designing of dual language books, and discusses the various factors that influence the design of dual language books.

\section{Dual Language Books}

First of all, it's important to understand what dual language books are, as they are of significance for language learners and/or bilingual readers. They offer texts in two different languages. Often, this text is side-by-side in each language, but some books will share a short excerpt, such as a chapter, prior to switching languages. Bilinguals all over the globe will show a fact that their fluent degree in different languages is not the same. A language which is mainly used in academic circumstances may seem strange while used in informal circumstances. Family problems are usually talked in a home language. Based on where a couple lives while their first baby is born, they may merely grasp the vocabulary for baby items in one language and find it hard while talking with families in their country of origin. However, the notion of a "balanced bilingual" is not really put into practice completely in the field of multilingualism. In spite of this, people may be caught in the trap of holding that bilingual children are exceptions to this rule. They have such an expectation that bilingual children have the same level of mastery of both languages. Nevertheless, similar to adults, children's level of linguistic ability varies with circumstances and languages. For instance, it is a challenge for a bilingual child to illustrate issues in a home language which occurred in the school language. This is due to the fact that there are differences in the words, phrases and meanings between the school setting and the home setting.

According to Walker, Edwards and Blacksell (1996), dual language books provide a good example of "Language in contact". For language learners, dual-language books are an optimal reading option as they are less daunting in comparison to reading fully in the target language. Reading in a foreign language can be intimidating for even experienced learners. However, if there is an English translation handy, it's much easier for people to give reading a try without fear of failure. Because they offer additional language support, dual-language books are perfect for beginners and intermediate students. Books in different languages play a significant part in a child's experience of other languages and scripts. Research has demonstrated that helping bilingual children to build literacy in more than one language requires the willingness of parents and teachers to take the maximum advantage of the considerable benefits brought by bilingual books (Baker, 2011, vol. 79). In the past, there was much criticism regarding the use of dual and multi-language texts stating that it would simply encourage the children to focus only on the easier language. However, nowadays, it has been widely recognized that dual language books are an effective way to support children in their bilingual journey. Children can make a comparison between the 
native and the foreign language. In this process, they can find out the translation mistakes and learn new words. Moreover, they can recognize how much they have known already. Dual language books can help to create interesting language lessons where children can learn not only by hearing and imitating but also by reading and imitating. Recent studies have found that children who read dual texts develop the ability and skills to transfer literacy concepts that they have been developing in one language to another, thereby promoting the overall literacy development of their skills (Edwards, 2008, vol. 5). Prof Xiao-lei Wang has further offered two examples of how dual language books and materials can help primary school children master their languages. The first example is that the dual language books offer predictability to another language from the primary language. The use of dual texts promotes comprehension and also introduces children to the different ways in which prints work.

The second example is that dual language books offer the opportunity of comparing and contrasting texts and also help to develop meta-linguistic abilities. This is referred to as the ability to notice the differences and variances in different languages. With the availability of bilingual books in the classroom and also at home, children are provided with the opportunity of becoming literate in a fluid and an organic way. They are enabled to use both languages in a good manner for the development of overall comprehension. By reading the same books and discussing the plot in their own languages, parents and teachers can further strengthen this process (Walker, 2014).

Considering schools in the UK where the appearance of dual language books can date back to the early 1980s, research has highlighted that monolingual teachers often feel insecure in giving school children books and scripts and languages that they themselves are unable to understand (Edwards \& Blacksell, 1995). Due to the lack of detailed knowledge and information about other cultures and languages, they have expressed a lack of confidence in talking to children about the stories and books they are reading in other languages. Dual language books, therefore, have offered children and teachers good alternatives as the English text can allow equal access to bilingual and monolingual readers.

\section{The Need for Dual Language Books in UK Primary Schools}

The use of dual language books in schools, indeed, has brought about key issues of concern. While effective resources may be critical for the success of the children, they tend to work only in schools where linguistic diversity is deemed as an asset rather than an issue. Here, the teachers recognize that the appropriate resources may not be the only answer and instead exist as just a part of a wider response.

According to existing studies which have been conducted with teachers and students of schools in the United Kingdom, it has been found that there are various perceptions regarding the place of dual language books within a classroom (Ma, 2008: pp. 237-251). Furthermore, it has been determined that one language 
that needs to be kept a part of the books is English as it is the primary language of the country. Nevertheless, the secondary language should be the community language or a common language spoken in the environment such as French and Welsh.

One of the primary benefits of dual texts that have been identified by teachers is the improvement in student awareness of multi-culturalism. In addition, dual texts are also viewed as a valuable bridge between the school and the home, making it possible for the parents and also other literate members of the community to be able to read with their children. As claimed by Walker, Edwards and Blacksell (1996), many teachers in the UK believe that dual language books are in no way helpful in teaching the community language mainly because they have been encouraging the children to focus on one language at the price of another.

In spite of this, it has been found that to guarantee the success of dual language books in schools, it is critical for those who source and produce these resources to focus on the design and the structure of the texts, images and the book as a whole. Key issues needing special attention are concerned with the diversification of value orientation and the guarantee of an equal structure of the two languages while developing dual language books. Furthermore, the direction of the reading needs to be given attention as well. Thus, it will be easier for multi-linguistic and bilingual students to better understand the two languages and also relate to the texts and the scripts which are a critical part of the book. Also, from the perspective of teachers, the use of languages will help them in reading in the language that the children can understand best and alternating to the second language so that they are able to facilitate discussion and ensure progress and development.

\section{The Diversification of Value Orientation in the Designing of Dual Language Books}

According to Baker and Jones (1998), in the designing of dual language books for children, the correct value orientation should be comprehensive and diversified. To be specific, it is necessary to integrate the knowledge, activity and experience organically to develop strengths and avoid weaknesses and design dual language books based on children's actual situation. Dual language book designers should not only pay attention to the knowledge already mastered by children and the activities they love with a view to stimulating their interest in reading and motivating them to read to the fullest extent, but also focus on the inherent logic and systematicness of both linguistic and non-linguistic knowledge of the two languages and spare no effort to meet children's all-round development and social development needs. In this way, they can improve the quality of bilingual education and promote the achievement of its ultimate goal.

In the United Kingdom, the diversification of value orientation in the designing of dual language books for children needs to be based on children's overall 
development. This does not mean that the child-center theory or the experience-center theory is advocated, but to highlight the significance of integrating children's all-round development and individuality with the teaching of bilingual and non-bilingual knowledge to them and also the connection between bilingual ability training and morality. Moreover, importance should also be attached to the interaction between the disciplinary system, social needs and children's ability development. The development of children, especially their cognitive level, cannot be separated from the acquisition of non-linguistic knowledge and bilingual knowledge. Children's intelligence development is reliant on their knowledge impartment; without rich knowledge, intelligence cannot develop. Knowledge is the foundation of intelligent development. The dual language books for children should play a positive role in the all-round development of children, such as their listening and speaking skills. One can see clearly that to achieve diversification of the value orientation in the designing of dual language books, designers should not only focus on the overall and comprehensive conditions of children, but also take into account their individuality, interactivity and sustainability, thereby satisfying their development needs to the utmost extent.

\section{The Flexibility in the Designing of Dual Language Books}

Three-dimensional dual language books for children involve a new set of designing concepts, principles, objectives and methods. Guided by modern educational ideas, such as modern learning theory, educational theory and educational communication theory, they are a series of books featured with the organic integration of print media, audio-visual media and electronic media. In terms of the knowledge system, three-dimensional dual language books should manifest three-dimensionalization of organizational contents and supporting contents. The organizational contents, as the core, are evolving constantly. Supporting contents are generally descriptive and auxiliary, depending on the difficulty of knowledge and the readers' ability to accept. Organizational contents are believed to be the "skeleton" of dual language books while supporting contents are interpreted as the "blood and flesh", which jointly construct a knowledge system with specific teaching functions.

\section{The Equal Structuring of the Two Languages}

After reviewing the relevant existing literature, it has been found that the designing of a bilingual book for children involves various issues pertaining to the typography ranging from the choice of various typefaces to the organization of the languages graphically. Furthermore, dual texts have been found to lead to more problems due to the fact that they cover pictures as well, such as the placing of pictures in the texts. As teachers, the designers of the books are interested in understanding how the people read (Hu, Chen, \& Li, 2012: pp. 52-57). They tend to offer extremely valuable insights and views on how the typography, 
layout and production features tend to hinder and enhance the readers' interaction with the text.

The analysis has further revealed the need for dual texts to be organized in several different ways such as sections of chapters, whole books, as the double-page spread and even as single pages. The most innovative method regarding the design of dual books has been found to occur on the whole book that enables the reader's conventional notion of what the book is about (Chumak-Horbatsch, 2012). A typical example is The Tunnel by Brian Wildsmith which is a dual textbook in English and French. The French text is found to be dominant as it is placed on top of the English text and is also highlighted in bold. Reading the book from one end includes the French to be dominant while reading the book from the other highlights the English text (Figure 1).

Another book that falls under this specific category is "The moving mango tree" where there is the equal status for both the languages running in different directions, thereby making two books into one. Repetition of the illustrations is also avoided. Instead, they are related across the two different texts appearing in English and in Urdu (Edwards \& Blacksell, 1995). Furthermore, the analysis also manifests that within the constraints of a page, there are several ways in which pictures can be organized with the text. The main factors that need to be considered while designing the book with images involve children's ability and age, their reading strategy, type of materials, and the necessity and the comprehensibility of the pictures. Moreover, it has been elaborated that the solution for the relationship between images and texts is not the only way as one approach may suit a wide range of purposes (Hélot \& Young, 2006: pp. 60-90).

\section{The Placement of the Pictures}

It has been found that a different dimension exists to the relationship which may

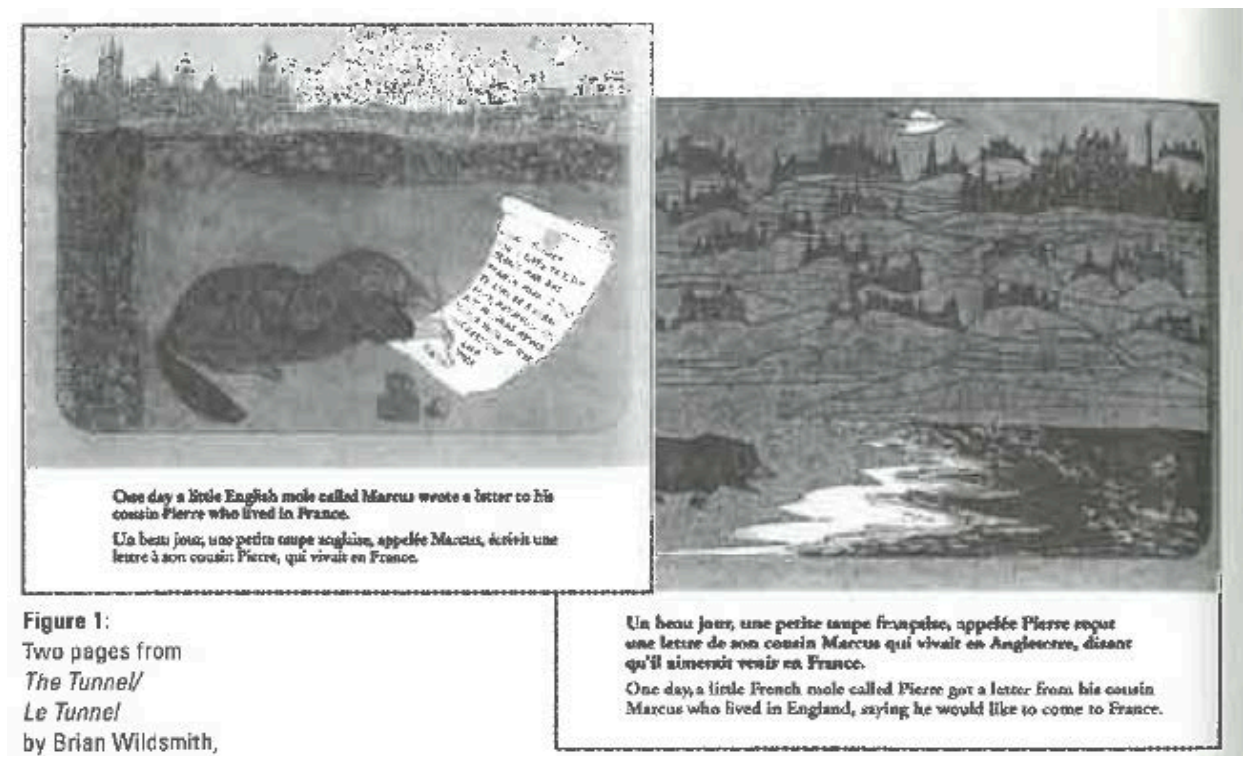

Figure 1. Two pages from The Tunnel by Brian Wildsmith. 
exist between the pictures and the words. This is mainly due to the fact that it does not just highlight a text/picture relationship, but a text/text/picture that needs to be configured. This results in the availability of different organization techniques. The most common way of the arrangement includes one text to be placed over the other in one of the three ways as shown in the image below (Figure 2).

The most commonly used techniques are the placement of one text over the other which is separated by space. The inclusions of images, nevertheless, increase the options for page layouts. In the meantime, the other configurations include the texts to be side-by-side while one text is vertical and the other is horizontal. This is used under the circumstance that the languages are read from different directions such as Urdu or Chinese (Figure 3).

\begin{tabular}{|c|c|}
\hline How the text is arranged & Visual configuration \\
\hline a directly above the other separated by space & 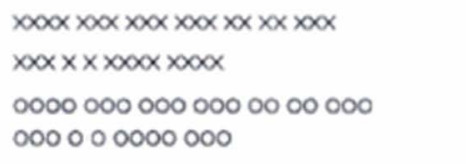 \\
\hline $\begin{array}{l}\text { b directly above the other separated by a line } \\
\text { or pattern }\end{array}$ & 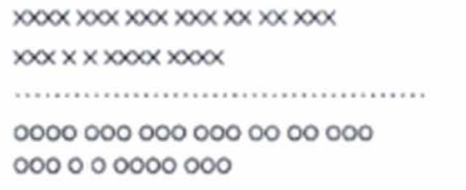 \\
\hline c above the other but staggered right or left & 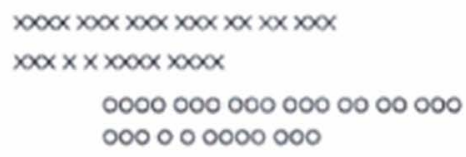 \\
\hline
\end{tabular}

Figure 2. Arrangement of texts.

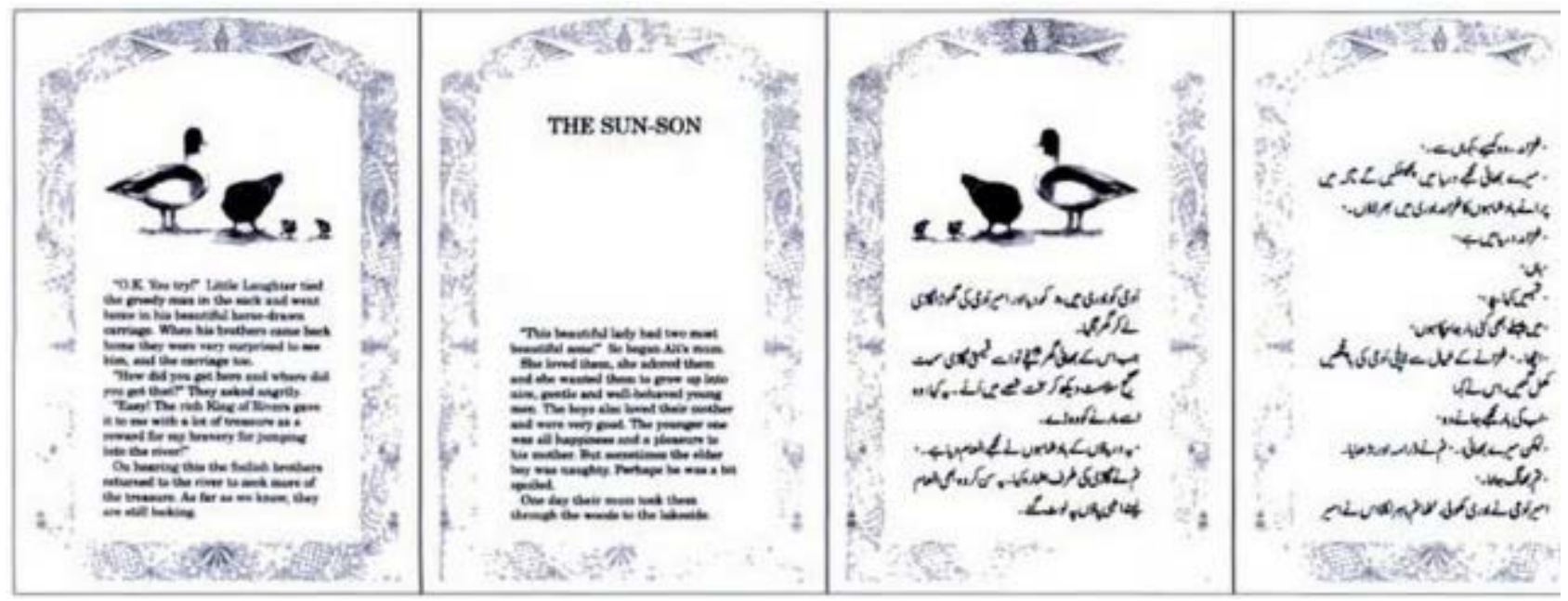

Figure 3. Direction of texts. 
Also, the analysis results reveal that the effectiveness of page designs is reliant on the way in which a book may be used. For instance, in school, dual texts have been observed in different situations with story time being the most common. This has been found to include a group with mono-lingual and bilingual children and two teachers (Figure 4). Occasionally, the whole story will first be read or paraphrased in one specific language and then the languages will be alternated by the other language after each page. It has also been observed that in some cases, readers will tend to choose the familiar language while reading (Newman, 1996: pp. 495-513).

These observations are found to be consistent with other studies. While bilingual and mono-lingual teachers work together, mono-lingual teachers retain the most control. On the other hand, when responsibilities are taken by bilingual teachers, they tend to be more capable of ensuring that the children's home language is used throughout and that the same language is used to respond to the contributions of the children (Pitkänen-Huhta \& Pietikäinen, 2014). In spite of this, dual language books have been found to be used in different ways by bilingual children or monolingual children who may work alone and also by an individual monolingual and bilingual child.

\section{The Direction of the Reading}

Another common issue existing in the design of dual language books is typography. It has been found that dual texts offer a distinctive kind of typographic problems as compared to those in single-language books. The main reason behind this is the inclusion of two different texts rather than one and also the project

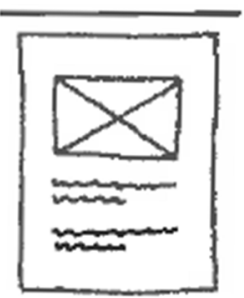

Layout 1 picture above both texts

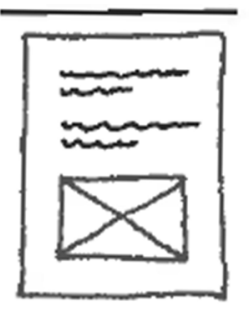

Layout 2 picture below both texts

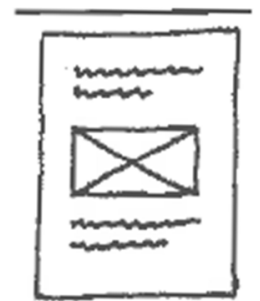

Layout 3 picture between both texts

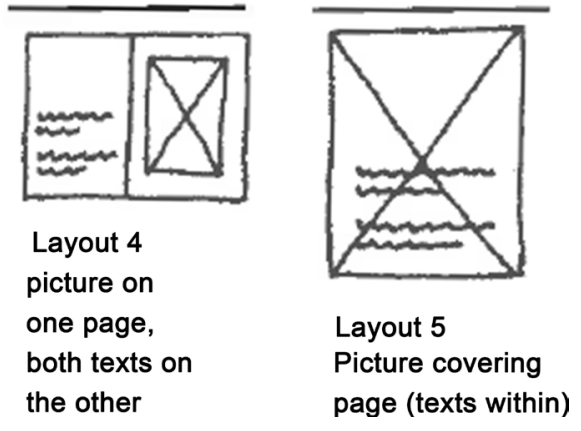

Figure 4. Ways of organizing texts and pictures. 
languages such as the usage of Latin as well as non-Latin alphabets. The analysis has demonstrated that the typographic treatment given to both the languages and also their placement on a single page can facilitate readers' understanding of both languages. The main factors affecting the typographic status have been found to be mode (typeset, handwritten or word processes text), size, amount of text and use of space. Ideally, in a dual text book, how each of these factors is dealt with can play a positive role in ensuring that both the languages are viewed as equally important (Ntelioglou, Fannin, Montanera, \& Cummins, 2015: p. 70). According to Walker, Edwards and Blacksell (1996), directionality is a design issue in dual texts when right-left reading languages are combined with left-right reading ones. They believe that most dual texts incorporating right-left reading languages tend to be produced within the book conventions of left-right languages. Readers of the Urdu part of a dual text, thus, need to open the book from the 'wrong' end. Some arrangements of text, however, allow for successful incorporation of right-left reading languages (Figure 5).

Apart from this, issues to be emphasized involve alignment problems and directionalities. Alignment problems tend to occur mainly when there is no enough attention on the relative sizes and the spacing of the type. On the other hand, directionality has been found to be a design issue when the right-to-left texts are combined with the left-to-right readings. In the case that languages are placed side by side, it is critical for the designer to be aware of the various scripts and their different graphic conventions. These sorts of mistakes may not only hinder children's development of reading abilities but at the same time, result in the delivery of negative messages. Hence, the checking of the texts in dual language books has been emphasized by teachers and parents that are aware of the conventions in language and also the significance of typographic factors in assisting the children to read adequately.

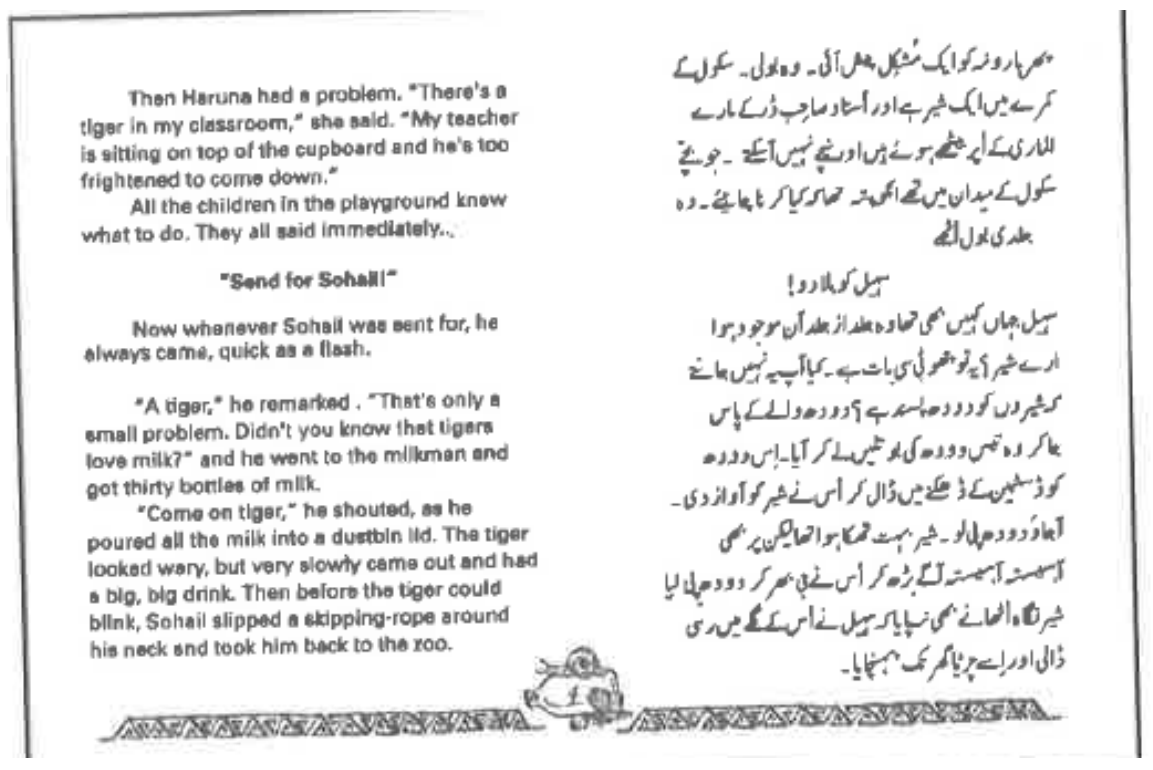

Figure 5. Different direction of the text. 


\section{Conclusion}

From this analysis, it can be concluded that the design of dual text for use in the United Kingdom's primary schools is neither straightforward nor simple and some key areas should be given special attention. The Multilingual Resources for Children Project at the University of Reading plays a positive role in the identification of many issues. Firstly, according to Walker, Edwards and Blacksell (1996: p. 282), successful dual texts are those where the potential readers have been made part of the design process. Attention should be paid not only to the overall and comprehensive conditions of children but also to their individuality, interactivity and sustainability. In other words, children's abilities and needs should be taken into full consideration. Secondly, more research is needed with regard to non-Latin script typography for children. Clearly, dual language books, if effectively designed, can boost the development and the progress of the bilingual child's mind towards literacy and may also address issues such as differences between the home setting and the school setting facing bilingual children. The use of dual language books has also been found to be helpful for teachers and parents as it assists them in reading and understanding what a child learns. This makes it easy for them to relate to the specific experiences of the children in question. Based on the above analysis, what should be noted is that it is of necessity for education policy makers and administrators to provide continued support for the identification, production and provision of important resources, in order to develop a progressive multi-cultural society like that found in the United Kingdom today.

\section{Conflicts of Interest}

The author declares no conflicts of interest regarding the publication of this paper.

\section{References}

Baker, C. (2011). Foundations of Bilingual Education and Bilingualism (Vol. 79). Bristol: Multilingual Matters.

Baker, C., \& Jones, S. P. (1998). Encyclopedia of Bilingualism and Bilingual Education. Philadelphia, PA: Mulfilingua Matters Ltd.

Chumak-Horbatsch, R. (2012). Linguistically Appropriate Practice: A Guide for Working with Young Immigrant Children. Toronto: University of Toronto Press.

Edwards, V. (2008). Multilingualism in the English-Speaking World: Pedigree of Nations (Vol. 5). Hoboken, NJ: John Wiley \& Sons.

Edwards, W., \& Blacksell, R. (1995). Multilingual Resources for Children Project. In Building Bridges: Multilingual Resources for Children (pp. 112). Bristol: Multilingual Matters.

Hélot, C., \& Young, A. (2006). Imagining Multilingual Education in France: A Language and Cultural Awareness Project at Primary Level. In Imagining Multilingual Schools: Languages in Education and Globalization (pp. 69-90). Bristol: Multilingual Matters. https://doi.org/10.21832/9781853598968-004 
Hu, R., Chen, X., \& Li, X. (2012). Exploring Bilingual Books with Five Chinese First Graders: Children's Responses and Biliteracy Development. Reading Horizons, 52, 57.

Ma, J. (2008). "Reading the Word and the World"-How Mind and Culture Are Mediated through the Use of Dual-Language Storybooks. Education, 36, 237-251. https://doi.org/10.1080/03004270802217686

Newman, S. B. (1996). Children Engaging in Storybook Reading: The Influence of Access to Print Resources, Opportunity, and Parental Interaction. Early Childhood Research Quarterly, 11, 495-513. https://doi.org/10.1016/S0885-2006(96)90019-8

Ntelioglou, B. Y., Fannin, J., Montanera, M., \& Cummins, J. (2015). A Multilingual and Multimodal Approach to Literacy Teaching and Learning in Urban Education: A Collaborative Inquiry Project in an Inner City Elementary School. Frontiers in Psychology, 5, 533. https://doi.org/10.3389/fpsyg.2014.00533

Pitkänen-Huhta, A., \& Pietikäinen, S. (2014). From a School Task to Community Effort: Children as Authors of Multilingual Picture Books in an Endangered Language Context. In C. Helot, R. Sneddon, \& N. Daly (Eds.), Children's Literature in Multilingual Classrooms (pp. 138-153). London: Trentham Books.

Walker, S. (2014). Typography \& Language in Everyday Life: Prescriptions and Practices. London: Routledge. https://doi.org/10.4324/9781315839332

Walker, S., Edwards, V., \& Blacksell, R. (1996). Designing Bilingual Books for Children. In Visible Language 30.3 (pp. 269-283). Providence, RI: Rhode Island. 